University of St. Thomas, Minnesota

UST Research Online

Accounting Faculty Publications

Accounting

6-2010

\title{
My Money or Yours: House Money Payment Effects
}

Larry Davis

University of St. Thomas, Minnesota, Irdavis@stthomas.edu

Patrick Joyce

Matthew Roelofs

Follow this and additional works at: https://ir.stthomas.edu/ocbacctpub

Part of the Accounting Commons

This Article is brought to you for free and open access by the Accounting at UST Research Online. It has been accepted for inclusion in Accounting Faculty Publications by an authorized administrator of UST Research Online. For more information, please contact asle4660@stthomas.edu. 


\title{
My money or yours: house money payment effects
}

\author{
Larry R. Davis • B. Patrick Joyce • \\ Matthew R. Roelofs
}

Received: 13 June 2008 / Accepted: 25 February 2010

(C) Economic Science Association 2010

\begin{abstract}
This paper reports the results of an experiment designed to study how subjects' decision making may be affected by the timing of participation payments (or show-up fees). The experiment follows Davis et al. (J. Econ. 30:69-95, 2004) where subjects were asked to make a sequential purchase decision and were given the opportunity to purchase information about the value of a good prior to a decision to purchase the good itself. There, subjects purchased information less often than expected which was interpreted as risk-seeking behavior. Here, we test a payment hypothesis by varying the timing of the participation payment. Payment of a show-up fee before the decision-making stages of the experiment increases information purchase, which we interpret as an increase in risk-averse behavior.
\end{abstract}

Keywords Payment timing · Information · Decision uncertainty · Show-up fee · Participation payment

JEL Classification B40 · C91 · D80

Electronic supplementary material The online version of this article

(doi:10.1007/s10683-010-9235-7) contains supplementary material, which is available to authorized users.

L.R. Davis · B.P. Joyce

School of Business and Economics, Michigan Technological University, Houghton, MI 49931, USA

L.R. Davis

e-mail: 1rdavis@mtu.edu

B.P. Joyce

e-mail: pjoyce@mtu.edu

M.R. Roelofs $(\bowtie)$

Department of Economics, College of Business and Economics, Western Washington University,

Bellingham, WA 98225, USA

e-mail: matthew.roelofs@wwu.edu 


\section{Introduction}

Paying experimental subjects a portion of their earnings as a fixed amount to induce volunteering is a common practice among experimental economists. Friedman and Sunder, in their book Experimental Methods: A Primer for Economists (1994), state: "Subjects prefer to be paid in cash" (p. 81), but never mention timing of payments. This oversight is probably accidental, but does leave the impression that payment timing is incidental to more important procedures in doing experiments. Furthermore, the possibility that the timing of payments to experimental subjects in general, and the timing of any fixed amounts in particular, could affect behavior has received little attention in the literature. This paper analyzes whether differential timing of these 'participation' payments or 'show-up' fees influences behavior in a sequential decision experiment where subjects could accept a varying level of risk by purchasing (or not) information about the value of a good prior to purchasing it.

In most experiments, the participation payment or show-up fee amounts to 5-30\% of a subject's total compensation, with the remaining earnings determined, at least in part, by subjects' actions in the experiment and some random effects. Most researchers use these payments as an aid to recruiting subjects and/or to demonstrate credibility with regards to making cash payments, the latter being particularly important at institutions where research experiments in economics are not widely used or understood by subjects. $^{1}$

Despite the widespread use of these types of payments, there is no consistent methodology for how or when to make them. Some researchers make the payment up front, in some cases even before subjects enter the room where the experiment will take place, with cash given to subjects for just 'showing up.' In other cases, the participation payment is simply announced in the instructions or during the recruitment process and is then added to the subjects' experimental earnings as one lump sum at the conclusion of the experiment.

To better understand the habits of experimentalists in this area, we sent an email questionnaire to ask authors of papers in recent issues of this journal about their work. We contacted all authors whose papers appeared in Experimental Economics in 2006 or 2007. Of the 44 papers published, we received replies from 20 authors, 18 of which were appropriate for our questions. Of those 18 papers, 14 authors indicated paying a show up fee (usually \$5US), with 12 paying the show-up fee as part of the final payment and two paying up front. In addition, most authors indicated that it was habit or ease of administration that drove their decision about when to pay the show-up fee. This information is, of course, anecdotal but it serves to highlight three key points. First, show-up fees are widely used; second, there is variability in how they are paid; and third, by and large, the specific decisions about how and when to make this type of payment may not be as carefully controlled as other aspects of experimental design.

This paper investigates whether the way in which subjects are paid for participation affects their willingness to make risky decisions. In particular, if subjects are paid

\footnotetext{
${ }^{1}$ There does seem to be a bit of movement in the field towards avoiding these payments altogether and instead increasing the size of the payments made as part of the incentive structure of the experiment itself.
} 
upon arrival, do they consider that money theirs? Alternatively, does adding the participation payment to their experimental earnings and paying them at the termination of the experiment induce a 'house money' effect? Particularly, does the ownership of the earnings affect the subjects' decisions, with subjects willing to make more risky decisions with 'house' money as compared to money that is 'theirs?' Also, in addition to this possibility of a house money effect 'in the large,' the sequential nature of the experiments reported here allows us to look for house money (and other) effects from period to period, or 'in the small.' Finally, we can compare whether these 'in the large' and 'in the small' effects can reinforce or offset one another.

We investigate this issue in the context of an experiment that examines individuals' willingness to purchase assurance information. Assurance information is defined as "... independent professional services that improve the quality of information, or its context, for decision makers" (AICPA 2002). The most common form of assurance information is an audit opinion. The experiments here are intended to represent a market for assurance services offered by accountants in which information is available for purchase that reduces the variance in the range of possible values for a good. This experimental setting is particularly appropriate for investigating the effects of participation payment timing on risky behavior since subjects' decisions to purchase or not purchase assurance information relate primarily to the acceptance or mitigation of risk.

Our primary result is that paying subjects their show-up fee up front does lead to moderately more risk-averse behavior. Subjects provided the opportunity to reduce the variability of a risky choice at a more than fair price typically do so more frequently when they have been paid their participation payment at the beginning of the experiment. Furthermore, even though purchasing information is characteristic for our subjects, the incidence significantly increases when the subjects are paid prior to making decisions. The incidence of information purchase increases from $55 \%$ to $63 \%$ and the incidence of subjects who always purchase information increases from $23 \%$ to $31 \%$.

These results have implications for both experimental economics research and for those interested in selling assurance information (e.g., the public accounting profession). With regards to experimental economics, the implication is that even though the timing of show-up fees should normatively not affect behavior, it may affect the extent to which subjects exhibit risk-avoidance in their decision making. This would suggest that, particularly in experiments where subjects' risk preferences could play a role, researchers should give careful thought to both if and when to make participation payments, and perhaps in some cases introduce a treatment to specifically test for any possible effects of payment timing. With respect to the market for assurance information, the implication is that demand for assurance information is likely to be greatest among decision makers who perceive their possible decision outcomes as including both gains and losses rather than those who perceive their possible outcomes as consisting primarily of gains of varying magnitude. 


\section{Literature}

The experiments reported here build on an earlier set of experiments discussed in Davis et al. (2004) (hereafter DEJ) in which subjects were presented with the opportunity to purchase a fictitious good whose value is determined by a random draw from a known uniform distribution. The good's price was the distribution's mean. After five decision periods, subjects were provided the opportunity to purchase information about the draw prior to deciding whether to purchase the good. The information provided was either the exact value of the draw (referred to as certain information) or a value which had a $80 \%$ probability of being the exact value of the draw and an $20 \%$ probability of being a value less than or equal to the draw (referred to as uncertain information). Information was priced lower than its fair value. Davis el al. (2004) observed subjects purchasing information less often than expected while showing some price sensitivity. ${ }^{2}$ This reluctance to purchase information while purchasing the unknown valued good is interpreted as risk-seeking behavior.

Thaler and Johnson (1990) investigate how the results of prior decisions affect subsequent decisions. They find prior gains can increase a subject's willingness to accept risk, which they label the 'house money effect.' Prior losses can also lead to more risky choices when a positive result allows the subject to recoup the loss, 'breaking even,' or it can lead to less risky choices when that opportunity is not available, which they term 'preserving the status quo.' Staw (1976), on the other hand, finds prior losses may lead to more risky subsequent choices, which he refers to as 'escalation of commitment.' Finally, Weber and Zuchel (2005) present experimental results that suggest that the response depends on the framing of the problem with escalation of commitment behavior more likely when the decision problem is presented in a portfolio-choice format, and house money effects more likely when the problem is presented as a lottery.

Six recent papers are most closely related to our work here. Clark (2002) directly studies the possibility of a house money effect in a public goods game. Two treatments were run - one in which subjects used their own money to fund the experiment (with an unannounced payment made at the end to keep overall earnings constant with the other treatment) and the second in which subjects used money provided to them at the beginning of the experiment. The author reports no significant differences across the two treatments using non-parametric tests that use each session or first round individual data as an observation. Harrison (2006) applies to the same data a panel hurdle model (house money effects on the decision to give anything, then conditionally on how much to give) using all individual data as observations. He finds that house money slightly reduced the probability of subjects contributing anything, but had no effect on the contributions of those who gave something. Ackert et al. (2006) present results from an experiment that show evidence of house money effects based on the level of cash endowment in an asset market experiment. These examples compare most closely to our 'in the large' version of a house money effect generated by the timing of the participation payment.

\footnotetext{
${ }^{2}$ In these experiments information was priced near but less than fair value for certain information and even lower for uncertain information. Subjects appeared to react to the change in price more than the change in quality.
} 
Cherry et al. (2005) take a different perspective on the source of a house money effect and look at whether the origin of subjects' endowments affect their willingness to contribute in a linear public goods game. The treatment involves subjects either earning their endowment as the result of their score on a quiz or having their endowment simply given to them. They find that subjects contribute about the same amount regardless of whether or not their endowment is earned or is a windfall gain.

Finally, a pair of papers by Harrison et al. $(2007,2009)$ take the idea of a house money effect further when they consider the role that a non-stochastic show-up fee might have in counteracting the possibility that the randomization across individuals and treatments, crucial to proper experimental technique, may draw a sample of subjects that is more risk seeking than the population as a whole. Their results show that the use of a show-up fee does result in samples of subjects that are more risk averse than the underlying population as measured by a survey of the adult Danish population conducted in 2003 .

\section{Experimental procedure}

Subjects were given the option of buying or not buying, at a posted price, one unit of a good whose range of possible values was $U[40,50]$ changing in unit increments (i.e., 40, 41, 42, 43 and so on). The distribution was common knowledge but the exact redemption value was not known at the time of the purchase decision. The price of the good was set at the mean of 45 francs. The value of the good in each round was determined by the draw of a ball from a bingo cage and revealed to the subjects after they had chosen to purchase or not purchase the good. For the first five decision periods, subjects made purchase decisions without the opportunity to purchase information. Starting in period 6 and continuing for 8 periods, subjects were provided with the opportunity to purchase assurance information-information about the value of the good-prior to deciding whether or not to purchase the good. They did not know the exact number of decision periods, but knew approximately when the experiment would end. In all cases we finished well before the allotted time, but cannot rule out the possibility of an end-of-game effect. ${ }^{3,4}$

The experiment is organized in a $2 \times 2$ factorial design with the timing of the participation payment and quality of information as treatments. In the payment timing treatment, one half of the sessions involved paying the subjects in one lump sum (participation + experimental earnings) at the end of the experiment. This is a subset of the Davis et al. (2004) data and is taken directly from their study. In the other half of the sessions subjects were paid their participation payments upon arrival at the experiment. In particular, subjects were given their participation payment in cash and instructed to place it in their pockets or purses. They were informed that the experiment would not proceed until their money had been put away. ${ }^{5}$

\footnotetext{
${ }^{3}$ There were always many unused spaces on the subjects' decision sheets when the experiment terminated.

${ }^{4}$ The experiment instructions are available online at the Experimental Economics website.

${ }^{5}$ There was a noticeable tendency by many subjects to place the money in front of them on the table. Since it was not clear to us whether money on the table was 'theirs' or still 'ours,' we made them take physical possession before continuing.
} 
Table 1 Experimental design—number of subjects by treatment

\begin{tabular}{llll}
\hline & & Payment timing & \\
\cline { 3 - 4 } & & Before & After \\
\hline Information & Certain & 35 & 27 \\
Quality & Uncertain & 31 & 31 \\
\hline
\end{tabular}

In the second treatment, information quality takes two values-certain and uncertain. In the case of certain information a subject who decides to purchase information is provided with the exact value of the good. Given the range of values of the good and its fixed price, the risk-neutral value of the information is 1.36 francs. This option was offered for a price of 1.25 francs. In the uncertain information treatment purchasing information provides the subject with a smaller range of values for the item, effectively reducing the variance. Inclusion of the uncertain information treatment allows for a check on the robustness of our results to conditions representative of those that prevail in the actual market for assurance services. A subject who purchases information in this case receives information that is the actual value of the draw $80 \%$ of the time and is less than or equal to the actual value $20 \%$ of the time. For example, if the subjects were given the value ' $45,80 \%$ of the time the value of the draw was 45 and $20 \%$ of the time the value was 45 , or 46 , or 47 or 48 or 49 or 50. This was explained to the subjects in the written experimental instructions and emphasized by the experimenter at the beginning of the experimental session when reviewing the instructions. The risk-neutral value of information in the uncertain information treatment is 1.10 francs and subjects could exercise this option for 1.00 francs. In this experiment all decisions about information purchase, as well as the purchase of the good, are private.

The first set of experiments was conducted by hand at Michigan Technological University between October 2002 and December $2006 .{ }^{6}$ Each session lasted between 60 and 75 minutes and average earnings were $\$ 8.38$ (including the show-up fee) with a range of $\$ 3.75$ to $\$ 12.00 .^{7}$ Table 1 summarizes the experimental design and includes the number of subjects in each treatment.

\section{Hypotheses}

Our primary research question is whether the payment of the show-up fee before the experiment begins leads to less risk acceptance (fewer risk-seeking choices) by subjects. Accepting risk in this context is not purchasing information prior to making a decision to purchase or not purchase the good. We argue that paying the participation payment and forcing subjects to take possession of it transforms 'house money' into 'their' money and makes them less willing to make risky choices. In addition,

\footnotetext{
${ }^{6}$ We conducted an additional set of experiments in response to a referee's comment. The second set of experiments is described in Sect. 6.

${ }^{7}$ Since the choice being made was over a nearly fair gamble the expected payoff from the decisions themselves was between zero and $\$ 1$.
} 
since Davis et al. (2004) found that the price of information influenced information purchase, with subjects more willing to purchase less expensive (and lower quality) information, we wondered if the quality of information and payment treatment are independent from each other. There appears to be no a priori reason to expect the two treatments to be related, so this is an empirical question. Based on this discussion, the primary hypotheses under consideration are as follows.

H1: House Money (macro)—Payment of the show-up fee before the experiment does not affect information purchase.

$\mathrm{H} 2$ : Information quality does not affect information purchase.

H3: Information quality does not affect information purchase conditional on payment of the show-up fee before the experiment.

H4: Payment of the show-up fee before the experiment begins does not affect the rate at which subjects purchase the good without first purchasing information.

\section{Results}

A total of 124 subjects recruited from undergraduate classes at the sophomore, junior and senior level at Michigan Technological University participated in the main part of the study. Including only the final eight decision periods when information was available for purchase results in a final sample totaling 954 usable observations. The two independent variables are the time when subjects are paid their show up fee (at the beginning or end of the experimental session) and the quality of information (certain or uncertain). The primary dependent variable of interest is if the subjects purchased information; of secondary interest is if they purchased the good. Descriptive statistics by treatment are presented in Table 2 .

Further descriptive statistics by decision are given in Fig. 1, which presents data on the choices by payment treatment and indicates that subjects bought information $59 \%$ of the time and tended to buy information more frequently when they were paid at the start of the experimental session. ${ }^{8}$ The data also show that the number of subjects who buy information every period rises when information is uncertain (from $11 \%$ to $36 \%$ ). This is consistent with Davis et al. (2004) and suggests that subjects are more sensitive to the price than quality (certainty) of information; subjects tended to purchase information more frequently when it was less certain, but cheaper.

Table 2 Percentage of subjects purchasing information per period by treatment (standard deviation)

\begin{tabular}{llll}
\hline & \multicolumn{2}{l}{ Payment timing } \\
\cline { 3 - 4 } & & Before & After \\
\hline Information & \multirow{2}{*}{ Certain } & 0.54 & 0.47 \\
quality & & $(0.49)$ & $(0.50)$ \\
& \multirow{2}{*}{ Uncertain } & 0.71 & 0.62 \\
& & $(0.45)$ & $(0.62)$ \\
\hline
\end{tabular}

\footnotetext{
${ }^{8}$ Note we are distinguishing between the number of subjects buying information and the number of times information was purchased. Both increased when payment preceded decisions.
} 
Fig. 1 Subjects' decision tree by treatment (pooled across information conditions)
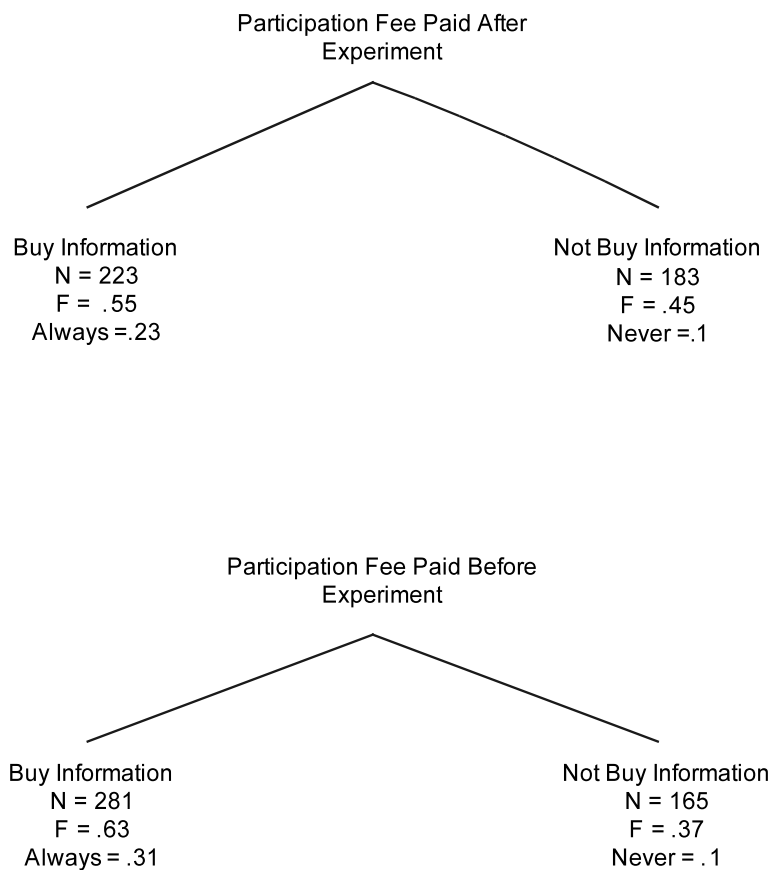

$\mathrm{N}=$ number of observation $\mathrm{F}=$ relative frequency

This summary data is certainly suggestive of an effect of the two treatments on subjects' behavior. To explore these effects more formally, we present a series of results that addresses each of the hypotheses discussed in Sect. 4.

Result 1: Payment of the show-up fee prior to participation in the experiment is associated with more frequent information purchase.

Result 2: Information quality is associated with differences in the rate at which information was purchased.

Result 3: The difference in information purchase associated with differences in information quality is not conditional on the timing of the participation payment.

Support: To test the first three primary hypotheses, H1, H2, and H3, repeated measure ANOVA tests were performed to examine the relation between the rate at which information was purchased, and both (1) the time at which subjects were paid their show up fee and (2) the quality of the information available for purchase. These results are presented in Table 3; the results of logistic regression and nonparametric tests are consistent with those reported in Table 3. ${ }^{9}$ The main effects for both pay-

\footnotetext{
${ }^{9}$ To test the robustness of our results to the use of alternative statistical techniques, we reran our analysis using both logistic regression and nonparametric tests. As in the original analysis, the dependent 
Table 3 Differences in information purchase rates across treatment conditions

\begin{tabular}{llll}
\hline Factor & $\begin{array}{l}\text { Degrees of } \\
\text { freedom }\end{array}$ & $F$-statistic & Probability $>F$ \\
\hline $\begin{array}{l}\text { Payment timing } \\
\text { Information }\end{array}$ & 1 & 5.56 & 0.016 \\
quality & 1 & 23.53 & $<0.001$ \\
$\begin{array}{l}\text { (Payment timing) } \\
\text { X (information quality) }\end{array}$ & 1 & 0.08 & 0.770 \\
\hline
\end{tabular}

ment timing and information quality are significant. The significant main effect for the timing of payment does not support $\mathrm{H} 1$ as payment of subjects before the experimental session begins does, in fact, result in increased information purchases. The significant main effect for information quality indicates that there was a difference in information purchase rates as well, which does not support $\mathrm{H} 2 .^{10}$ The interaction between payment timing and information quality is not significant and, therefore, H3 cannot be rejected. Subjects' greater sensitivity to the price of information (as compared to the quality of information) does not appear to be affected by payment timing.

Result 4: Payment of the show-up fee prior to participation in the experiment is associated with less frequent purchases of the good without first purchasing information, which we interpret as a reduction in risk-taking behavior.

Support: To test our final primary hypothesis (H4), we test for a difference across payment treatments in the rate at which subjects purchased the good without first purchasing information. Subjects who were paid before participating in the experiment were significantly less likely to purchase the good without first purchasing information (see Table 4) than were subjects whose show-up fee was added to their earnings and paid at the termination of the experiment.

The significant results that reject our first and fourth primary hypotheses (H1 and H4) are consistent with increased risk aversion when subjects are paid prior to participation as compared to when they are paid after participating. Not only are the differences statistically significant, they are meaningful. Figure 1 shows that although subjects buy information at a high rate independent of treatment, which we interpret, given its price, as risk-avoiding behavior, paying the show-up fee before making

variable is information purchase rate and the independent variables are payment timing and information quality. With logistic regression, both payment timing $\left(\chi^{2}=5, p=0.017\right)$ and information quality $\left(\chi^{2}=227, p=0.001\right)$ are found to be significantly related to the purchase of information (tests for differences across decision rounds using dummy variables are not significant). Tests for differences in the proportion of individuals purchasing information in the two payment timing conditions both overall $(t=2.33, p=0.021)$ and within the certain $(t=1.3, p=0.084)$ and uncertain $(t=2.0, p=0.024)$ information quality conditions are also significant. A nonparametric $\chi^{2}$ test for independence of treatment conditions is significant $\left(\chi^{2}=9.34, p=0.01\right)$ while the nonparametric Fisher's test for payment timing effects both without regard for information certainty $(p=0.029)$ and with both certain $(p=0.099)$ and uncertain information $(p=0.012)$ are also significant.

${ }^{10}$ As mentioned before, this result is consistent with subjects being more sensitive to price than to information quality. 
Table 4 Purchase of good without first purchasing information (risk-accepting behavior)

\begin{tabular}{llll}
\hline Factor & $\begin{array}{l}\text { Degrees of } \\
\text { freedom }\end{array}$ & $F$-statistic & Probability $>F$ \\
\hline Payment timing & 1 & 12.39 & $<0.001$ \\
Information & 1 & 0.38 & 0.540 \\
quality & & & \\
\hline
\end{tabular}

decisions increases information purchase approximately $15 \%$ overall and $35 \%$ for those subjects always purchasing information. ${ }^{11}$ Note that the payment treatment has no effect on those 'never purchasing information' only on those 'always purchasing.' Whether we interpret these risk-taking individuals as simply insensitive to these payment differences or, alternatively, as being supremely confident that they could determine when to purchase the good and when to abstain is an open conjecture. ${ }^{12}$

Note that these results present evidence in support of a house money effect 'in the large,' that is an effect generated by the timing of the participation payment itself on overall levels of information purchase. There are also potential effects of the largescale house money effect on the more micro-level decisions that occur from period to period that, confusingly enough, also includes the possibility of a house money effect 'in the small' (i.e. from period to period). In addition, it is possible to explore these period-to-period effects either by basing the analysis on a gain or a loss in the previous period and/or a cumulative gain/loss position at any given point in time.

The influence of prior results can be grouped into a number of categories. The two effects that we are most interested in are a house money effect and escalation of commitment. In this context, a house money effect is the purchase of the good without first buying information following a gain, or alternatively a cumulative gain. Escalation of commitment is purchasing the good without first purchasing information following a loss, or alternatively a cumulative loss. ${ }^{13}$ Other possibilities are present as well. Subjects can show regret if they purchase information following a loss caused by not

\footnotetext{
${ }^{11}$ Prior research (see Harrison and Ruström (2008) for a review) has addressed the question of how payoffs can affect individuals' risk avoidance behavior. This stream of research generally reports high rates of risk avoidance. For example, Holt and Laury (2002) report that in their low payoff condition about $2 / 3$ of their subjects exhibit risk-averse behavior. In this study we focus on how payment timing affects risk avoidance with respect to the purchase of uncertainty-reducing information. Our results indicate that, overall, subjects purchased risk-reducing information about 59\% of the time. However, subjects could also avoid risk by choosing to buy neither information nor the good (do nothing). If we classify both those who purchase information or who do not do anything as risk avoiders, the overall rate of risk avoidance in our study is about $75 \%$, with a range of $66 \%$ (certain information, payment after participation) to $87 \%$ (uncertain information, pay before participation).

12 As a note, the average ACT (one of two standardized college entrance exams used in the United States) test score of the student body from whom our subjects were drawn is 28 ; the national average score is about 21. Since we did not have the subjects do an exit interview we did not have an opportunity to ask them if they thought they could outsmart the game.

${ }^{13}$ Gains are easy to define but losses less so. A subject could experience a loss from purchasing the good without first buying information when the value drawn was less than the price. Alternately, a subject could buy information and discover the draw is less than the price and avoid a large loss, yet the price of the information is this period's loss. We have treated the losses differently. Our losses are from 'acts of commission' (buying the good) not 'acts of omission'.
} 
buying information yet buying the good. Reinforcement is the subsequent purchase of information after purchasing information in the prior round and avoiding a larger loss, or the subsequent choice to not purchase information after not purchasing it in the prior round while realizing a gain. ${ }^{14}$ Additionally, count your money and spoiled brat effects are possible. The former is not participating in a decision period following a gain and the latter is not participating following a loss. Finally, the break-even effect describes the purchase of the good without purchasing information in the last period(s) given the subject has a cumulative loss position and may be able to recoup her losses with a few lucky choices. ${ }^{15}$

Figure 2 presents decisions made by subjects in round $t+1$ given their decisions in round $t .{ }^{16}$ Note that house money and escalation of commitment effects occur with some frequency. In particular, decisions that can be characterized as leading to house money effects occur about $14-15 \%$ of the time in all subsequent decisions and escalation of commitment effects occur about $21 \%$ of the time in its respective branch (risk accepting). ${ }^{17}$

To examine possible escalation of commitment effects, we first test whether or not there is significant escalation of commitment effect based solely on a loss in the previous period. To do this we look at the rates at which subjects who did not purchase information and experienced a loss in period $t-1$ again purchase the good without first purchasing information in period $t$. As can be seen in Fig. 2, 70\% of subjects who do not purchase information and suffer a loss in period $t-1$ engage in escalation and again purchase the good without first purchasing information in period $t$. Most germane to the objectives in this study is that payment of the showup fee before participation in the experiment mitigated this affect. Subjects with a previous period loss who were paid before participating in the experiment were more likely to purchase information ( $t=2.43$ and $p=0.016$, two-tailed test) than were similar subjects who were paid their show-up fee at the conclusion of the experiment.

We also compare the rates at which subjects who have a cumulative loss purchase the good without first purchasing information across payment conditions. Subjects in a cumulative loss position were more likely to purchase the good without purchasing information when compared to those subjects with a cumulative gain. However, once again, the results indicate that subjects in a loss position who were paid prior to the start of the experiment were less likely to purchase the good without first purchasing information than were subjects who paid after the experiment was completed $(t=3.83$ and a $p=0.000)$. The intuition is that subjects in a current cumulative

\footnotetext{
${ }^{14}$ If the subject purchases information and then does not subsequently purchase the good, the price of information is his or her loss.

${ }^{15}$ The 'break-even' effect is complicated by the fact the subjects do not know the exact number of decisions they will make, but they do know the maximum amount of time allotted for the session.

${ }^{16}$ Note that one of the prior conditions of interest in Fig. 2 is whether subjects purchased information in the prior round. As information was not available until round 6, Fig. 2 reflects observations for only rounds 7 through 13.

${ }^{17}$ Figure 2 indicates that some of the possible effects (such as 'Spoiled Brat' or 'Regret') related to results from previous rounds happen fairly infrequently. These items are included for the sake of completeness, but are ignored in the analysis since the very small number of observations makes it difficult to draw conclusions on these issues with any degree of confidence.
} 

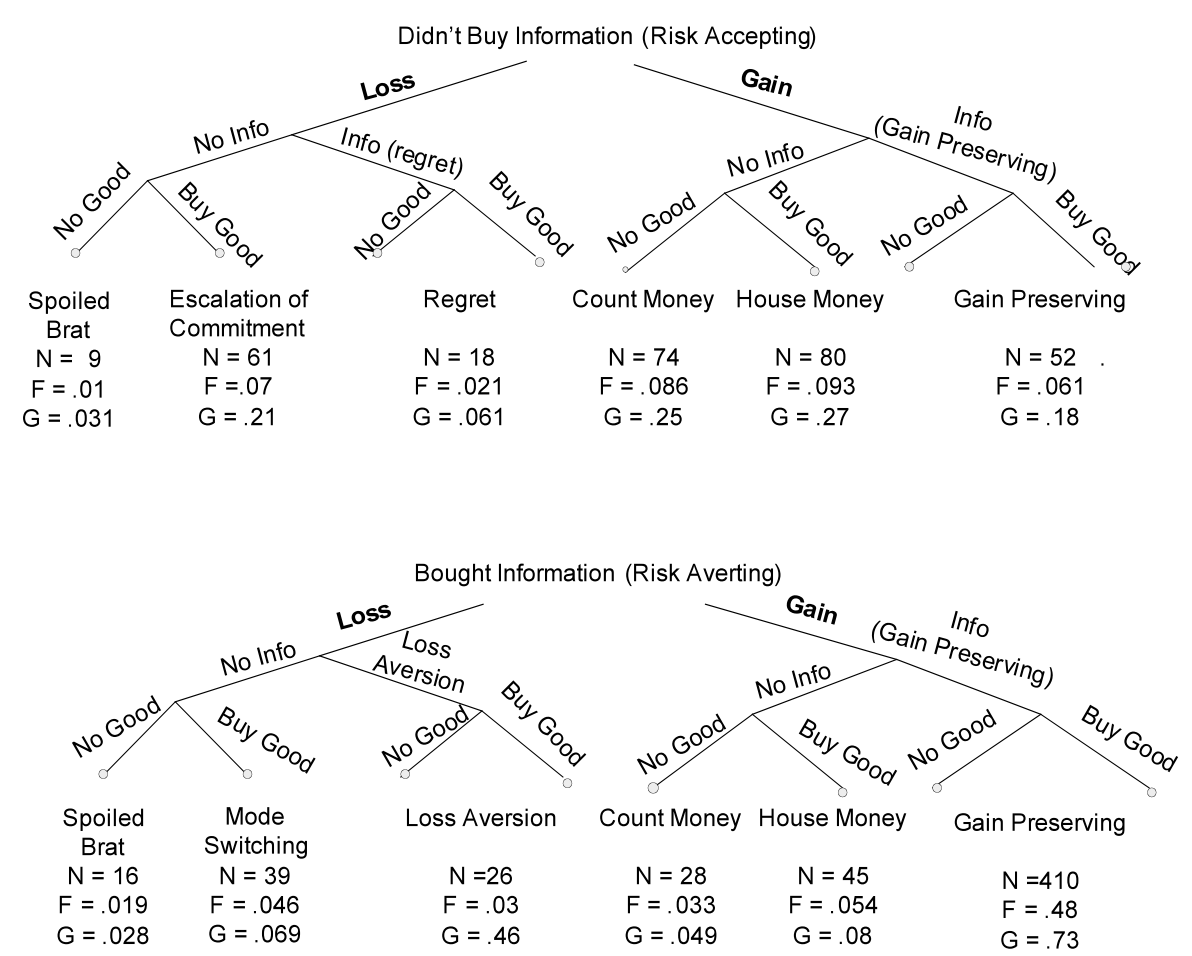

$\mathrm{N}$ - number of observations: upper branch 294,
lower branch 564 , total 858
$\mathrm{~F}$ - relative frequency of the total observations
$\mathrm{G}$ - relative frequency of branch observations

Fig. 2 Subjects' decision tree given previous round's action

loss position are going to be forced to return some of their show-up fee to the experimenters if the experiment terminates before eliminating these losses. Subjects who were paid before were more likely to reduce the risk of losing 'their' money by purchasing information.

With regards to house money effects 'in the small,' while we find that we observe them in the data (i.e. buying the good without buying information after a gain), there is no statistical evidence when we examine all subjects who earned a gain in period $t$ (or likewise had a cumulative gain at the conclusion of period $t$ ) and evaluate their decisions in period $t+1$.

\section{Discussion}

The primary result in the paper is that the procedural details of how and when a showup fee is paid in an experiment can have a significant effect on decisions. We attribute 
these differences to a house money effect in which subjects view a payment physically received at the beginning of the session as their own money while a payment simply promised to be paid along with the rest of their earnings is treated as house money. The primary effect of this house money in this case is that subjects purchase information less frequently (i.e. take more risk) when they are playing with house money.

The original formulation of the house money effect (Thaler and Johnson 1990 and Arkes et al. 1994) focuses on two key dimensions-subjects are more risk seeking when they receive: (1) small gains in income that are, (2) unanticipated. This leads to a potential ambiguity in our results. Is it possible that the payments that we made up front were unanticipated and therefore viewed as an unearned windfall gain while the payment made at the end of the experiment were viewed as part of the earnings for participating, effectively turning the house money explanation upside down? ${ }^{18}$ This is certainly possible and the terminology that we (all experimentalists) use to describe these payments highlights the potential ambiguity since these payments are alternatively referred to as a 'show-up fee' or 'participation payment.' In fact, we have followed that convention here and used both terms synonymously. But which is it? Is it a payment for simply showing up or is it a payment for participating in the experiment?

To address this issue, we offer two pieces of evidence in favor of our original interpretation. First, we briefly discuss the details of our recruitment process, and second we present the results of additional sessions in which we explicitly insert an unanticipated payment into the experiment to determine its effect.

First, with regards to recruiting, our procedure is for one of the experimenters to visit a class, make a short recruitment speech and, while the speech is being made, put up a slide on the screen with the text: "Subjects Wanted, \$8 show-up money+split a $\$$ pot, Less than 2 hour commitment, Time: late afternoon, Location TBA, Interested????, Email sample@univ.edu". This seems to make it very clear that subjects will be receiving $\$ 8$ for attending the session plus additional monies based on actions of themselves and others. It is difficult to see how the $\$ 8$ payment could be viewed as unanticipated in this case. This means that in the treatments presented in the main part of the paper, the focus of the house money effect is on the 'gains in income' part not on the 'unanticipated' part of the definition.

Second, this alternative interpretation of our results was interesting enough that we decided to explore it formally by running some additional sessions in which we purposely make the payment unanticipated and then vary payment timing within that treatment. ${ }^{19}$ To do this we simply repeated the experiment for six new sessions with the recruiting slide changed to read: "Subjects Wanted, Decision Making Experiment, $\$ \$ \$$ earnings potential, 2 hour maximum duration (afternoons only), INTERESTED??????, Email: sample@univ.edu" which makes no mention of any participation payment or show-up fee at all. Upon arrival at the experiment, subjects were

\footnotetext{
${ }^{18}$ Thanks are due to an anonymous referee for this suggestion.

${ }^{19}$ As with the earlier sessions these experiments were conducted by hand at Michigan Technological University between February and June of 2009. Each session lasted between 60 and 75 minutes. Average earnings were $\$ 8.10$ with a range of $\$ 6$ to $\$ 16$ (including the show-up fee).
} 
Table 5 Percentage of subjects purchasing information per period by treatment (standard deviation) [number of subjects]

\begin{tabular}{llll}
\hline & \multicolumn{2}{l}{ Payment timing } \\
\cline { 3 - 3 } & & Before & After \\
\hline Payment & Announced & 0.54 & 0.47 \\
announcement & & $(0.49)$ & $(0.50)$ \\
& & {$[35]$} & {$[27]$} \\
& Surprise & 0.33 & 0.24 \\
& & $(0.47)$ & $(0.43)$ \\
& & {$[22]$} & {$[15]$} \\
\hline
\end{tabular}

informed that they would be receiving $\$ 8$ for showing up and, as in the earlier sessions, the $\$ 8$ was paid before the experiment (subjects were instructed to put it in their wallet or purse) for three sessions and paid after (as part of their total earnings) for three sessions. In this context we have unanticipated, unearned windfall gains being distributed in two ways - one that makes the subjects more likely to view the payment as 'theirs' and one where it is left simply as a promise of future payment. ${ }^{20}$ Based on this new treatment, we are interested in testing the following hypotheses.

H5: House money (macro)—payment of the show-up fee before the experiment does not affect information purchase.

H6: Payment announcement does not affect information purchase.

H7: Payment announcement does not affect information purchase conditional on payment of the show-up fee before the experiment.

A set of summary statistics for the new data is presented in Table 5. Two observations are worth making. First, it appears that the primary result that paying the participation payment at the beginning of the session results in more information purchase is robust to the variation in whether or not that payment is announced in advance. Second, the new sessions in which the payment was not announced during recruiting (the surprise treatment) yield lower information purchase regardless of payment timing.

Based on this summary data it appears that there is an effect of both the payment timing and payment announcement treatments on subjects' behavior. We once again present a series of results from repeated measures ANOVA that address each of the hypotheses discussed above.

Result 5: Payment of the show-up fee prior to participation in the experiment is associated with more frequent information purchase.

Result 6: Payment announcement is associated with differences in the rate at which information was purchased.

Result 7: The difference in information purchase associated with differences in payment announcement is not conditional on the timing of the participation payment.

${ }^{20}$ All of the new sessions and subsequent analysis use information that is 'certain.' 
Table 6 Differences in information purchase rates across treatment conditions

\begin{tabular}{llll}
\hline Factor & $\begin{array}{l}\text { Degrees of } \\
\text { freedom }\end{array}$ & $F$-statistic & Probability $>F$ \\
\hline $\begin{array}{l}\text { Payment timing } \\
\text { Payment }\end{array}$ & 1 & 5.16 & 0.023 \\
$\begin{array}{l}\text { announcement } \\
\text { (Payment timing) }\end{array}$ & 1 & 34.70 & $<0.001$ \\
X (information quality) & & 3.56 & 0.829 \\
\hline
\end{tabular}

Support: To test these new hypotheses we again compare the rate at which information was purchased with both (1) the time at which subjects were paid their show up fee and (2) whether or not the show up fee was announced in advance. These results are presented in Table 6 . The main effects for both payment timing and payment announcement are significant. The significant main effect for the timing of payment does not support H5 as payment of subjects before the experimental session begins does, in fact, result in increased information purchases. The significant main effect for payment announcement indicates that there was a difference in information purchase rates as well, which does not support H6. The interaction between payment timing and payment announcement is not significant and, therefore, $\mathrm{H} 7$ cannot be rejected.

What do these results mean for the interpretation of a house money effect in our data? First, it appears that the gain in income that comes from paying the subjects at the beginning of the session results in more risk-averse behavior regardless of whether or not the payment is announced. By introducing the surprise payment treatment we control for the unanticipated part of the definition of house money and focus simply on whether subjects have made the payment 'theirs' or not. We interpret this as further support for our primary result. In addition, by explicitly introducing an unanticipated payment we would, based on a house money argument, expect to see more riskseeking behavior regardless of payment timing. This also is supported by the data. So while our original design contained potential ambiguities over the exact nature of the house money effect it does, based on this additional treatment, appear to be true in both dimensions. Finally, from a purely pragmatic methodological perspective, what is critically important is the fact that there is a significant and robust effect of the timing of the participation payment on subjects' willingness to accept risk. This implies that experimental economists would be well advised to carefully consider the amount and timing of any payments made for simply 'showing up.'

One final issue related to the interpretation of our results is the possibility that the increased information purchase observed when subjects are paid before the experiment could be due to a house-money-induced increased marginal propensity to consume (MPC) rather than to increased risk aversion. If our results are driven by an increased MPC, we would expect to observe increased purchases of the good both in the first five decision periods-which are treated as learning decisions-and in the following eight decision periods when information was not purchased. In both cases ( $p=0.05, p=0.03$ ) subjects purchased the good at lower rates when paid before the experiment than when paid afterwards. These results are inconsistent with an increase in the MPC and are consistent with increased risk aversion (i.e., subjects paid 
before participation were more likely to avoid the risk of a loss by choosing not to purchase the good).

\section{Conclusion}

The experiments reported here give evidence of a house money effect based on the timing of participation payments. We find that paying subjects their show-up fee upon their arrival at the experiment results in less risky behavior than when these payments are promised at the beginning, but not actually paid until the conclusion of the session. This result seems to be robust across a variety of other conditions such as information uncertainty and the whether or not the payment was anticipated. In addition, we find that the house money effect generated by the timing of the participation payment impacts the frequency of period-to-period escalation of commitment effects as well. The results here, taken together with those of Clark (2002), Harrison (2007), Ackert (2006) and Harrison et al. (2007, 2009), suggest that using participation payments at all and, in particular, how and when they are paid, is an important methodological issue that experimental economists should take seriously.

These experiments also suggest that the most likely buyers of assurance information will be decision makers for whom both gains and losses are salient. This would include, for example, individuals making decisions about investing their own retirement savings. Individuals for whom losses are not salient (or at least not as salient) will be less likely to purchase assurance information. This latter group would include, for example, managers who share in the profits from a business but do not necessarily realize a reduction in base salary in the event of a loss.

Acknowledgements We would like to thank the Faculty Research Fund at Michigan Technological University for providing the funding for the experiments. Western Washington University provided support for our research assistant, Stacey Dang, who worked diligently and carefully to compile the information from our email questionnaire. Colleagues Yvonne Durham and Daniel Hagen provided useful comments. Finally, the editor of this journal and two anonymous referees provided valuable feedback that has improved the paper significantly.

\section{References}

Ackert, L. F., Charupat, N., Church, B. K., \& Deaves, R. (2006). An experimental examination of the house money effect in a multi-period setting. Experimental Economics, 9(1), 5-16.

American Institute of Certified Public Accountants. (2002). Welcome to assurance services. http://www. aicpa.org/assurance/index, January 2002.

Arkes, H. K., Joyber, C. A., Pezzo, M. V., Nash, J. G., Siegel-Jacobs, K., \& Stone, E. (1994). The psychology of windfall gains. Organizational Behavior and Human Decision Processes, 59, 331-347.

Cherry, T. L., Kroll, S., \& Shogren, J. F. (2005). The impact of endowment heterogeneity and origin on public good contributions: evidence from the lab. Journal of Economic Behavior and Organization, $57,357-365$.

Clark, J. (2002). House money effects in public goods experiments. Experimental Economics, 5(3), 223231.

Davis, L. R., Elliot, S. R., \& Joyce, P. (2004). Assurance information: an experimental study. Journal of Economics, 30, 69-95.

Friedman, D., \& Sunder, S. (1994). Experimental methods: a primer for economists. Cambridge: Cambridge University Press. 
Harrison, G. (2006). House money effects in public goods experiments: comment. Experimental Economics, 10(7), 429-437.

Harrison, G., \& Ruström, E. E. (2008). Risk aversion in the laboratory. Research in Experimental Economics, 12, 41-196.

Harrison, G., Lau, M., \& Ruström, E. (2007). Estimating risk attitudes in Denmark: a field experiment. Scandinavian Journal of Economics, 109(2), 341-368.

Harrison, G., Lau, M., \& Ruström, E. (2009). Risk attitudes, randomization to treatment and self-selection into experiments. Journal of Economic Behavior and Organization, 70, 498-507.

Holt, C. A., \& Laury, S. K. (2002). Risk aversion and incentive effects. American Economic Review, 92(5), $1644-1655$.

Staw, B. M. (1976). Knee-deep in the big muddy: a study of escalating commitment to a chosen course of action. Organizational Behavior Human Performance, 16, 27-44.

Thaler, R., \& Johnson, E. J. (1990). Gambling with the house money and trying to break even: the effect of prior outcomes on risky choice. Management Science, 36(6), 643-660.

Weber, M., \& Zuchel, H. (2005). How do prior outcomes affect risk attitude? Comparing escalation of commitment and the house-money effect. Decision Analysis, 2(1), 30-43. 